\title{
Single-Center Study of 83 Horses with Suspensory Injuries Treated with Adipose-Derived Stem and Regenerative Cells
}

\author{
F. Ross Rich \\ Cave Creek Equine Surgical \& Diagnostic Imaging Center, Phoenix, USA \\ Email: drrich@cavecreekequine.com
}

Received 3 April 2014; revised 22 April 2014; accepted 28 April 2014

Copyright (C) 2014 by author and Scientific Research Publishing Inc. This work is licensed under the Creative Commons Attribution International License (CC BY). http://creativecommons.org/licenses/by/4.0/ (c) (i) Open Access

\begin{abstract}
Adipose-derived stem and regenerative cells (ADRCs), concentrated from autologous fat tissue, have the ability to differentiate into various specific cell types including tenocytes. In this retrospective study, clinical data are presented from 83 horses with 176 suspensory ligament injuries, treated with ADRCs, given a strictly enforced standardized rehabilitation program, and followed up for at least one year after returning to work. Assessment for a successful outcome was return to full work (RFW) at a previous or higher level of performance for one year or more without re-injury. RFW numbers were $\mathbf{8 4 . 6 \%}$ for horses with fore-limb ligament injuries and $\mathbf{8 2 . 1 \%}$ for horses with hind-limb injuries. RFW outcomes were slightly better in cases with proximal suspensory ligament desmitis (86.7\%) compared to horses with lesions of the body and branches. The ADRC injection procedure was well tolerated; no treatment-related adverse events, including injection flares, were detected in any of the $\mathbf{8 3}$ horses. The demonstrated long term stability of healed lesions strongly supports the therapeutic use of regenerative cells extracted from adipose tissue for treatment of acute and chronic, fore- and hind-limb suspensory ligament injuries in horses of various athletic sport disciplines.
\end{abstract}

\section{Keywords}

Suspensory Ligament, Adipose Stem Cells, Autologous Regenerative Therapy

\section{Introduction}

Inflammation of the suspensory ligament (suspensory desmitis) is a major cause of lameness in equine athletes 
involved in jumping, hunting, or racing activities. The equine suspensory ligament, along with the superficial and deep digital flexor tendons, functions as a weight-bearing, elastic tissue and plays two major roles: to support the metacarpophalangeal (fore-limb) and metatarsophalangeal (hind-limb) joints, and to store energy for spring-like motion [1].

The suspensory ligament consists of three segments: the proximal portion (origin), the body, and the branches [2]. Injury to the proximal portion of the suspensory ligament is reportedly more common in athletic horses whereas in racehorses the body or branches are more likely injured [3]. Standardbred and Thoroughbred racehorses with branch desmitis often continue to perform until injury progresses to involve the body of the ligament [4]. Suspensory ligament re-injury is reportedly more common in the hind-limb than that in the fore-limb [5]. Strenuous work beyond the level of fitness of the horse is believed to be the underlying cause of all suspensory ligament injuries.

Accurate diagnosis of suspensory ligament injuries requires diagnostic ultrasonography [6]. An evaluation of the limb should be made in both the longitudinal and transverse planes with comparisons made to the contralateral limb. Imaging controls on the ultrasound machine should be adjusted properly; otherwise, subtle tears in the ligament can be missed. Advanced training in ultrasound techniques and a high-quality ultrasound machine, are necessary to adequately evaluate the entire suspensory apparatus. Muscle and fat within the proximal suspensory ligament can sometimes be confused with injuries to the ligament. Hind-limb proximal suspensory ligaments are more difficult to image than fore-limb suspensory ligaments. Magnetic Resonance Imaging (MRI) is sometimes necessary to thoroughly evaluate the suspensory apparatus, particularly in hind-limb proximal suspensory ligament injuries.

Ligament healing typically involves inflammation followed by the deposition of scar tissue, rather than healing with normal ligamentous tissue. Although the continuity of the tissue may be restored, the affected ligament never regains the elasticity of normal ligament [1] [7]. This, together with the formation of constricting adhesions, predisposes a horse to re-injury and reduces its career longevity.

Stall rest, followed by controlled exercise to provide consistent loading of healing fibers is universally accepted as a necessary part of treatment for most suspensory ligament injuries [4]. For acute suspensory ligament injury, the rest period typically ranges from 30 days to 4 months [5]. Surgicaldesmoplasty with fasciotomy represents a more aggressive, surgical treatment option for suspensory ligament injury, which has been used for several decades to treat horses with refractory suspensory desmitis. Extracorporeal shock wave therapy (ESWT) has recently been added to the repertoire of the equine clinician for horses with suspensory injury that are refractory to conservative rest [4].

Autologous regenerative therapy is an innovative treatment approach aimed at reducing the risk of scarring, optimizing the strength of damaged ligaments, and allowing equine athletes to return to a high level of performance. Platelet rich plasma (PRP) is one form of autologous regenerative therapy that has been utilized in the treatment of suspensory ligament injuries [8]. The theory behind the treatment is that PRP adds endogenous growth factors directly to the injury site, thereby potentially facilitating healing and earlier return to sport following a musculoskeletal injury [8] [9].

Mesenchymal stem cells (MSCs) derived from bone marrowor, more recently, from adipose tissue (ASC), represent another form of autologous regenerative therapy that has been utilized in veterinary clinical practice in the treatment of ligament and tendon injuries for at least a decade. ASCs are capable of differentiating into multiple cell lines including bone, cartilage, tendon, and ligament in both in vitro and in vivo models [10] [11]. ASCs can differentiate into tenocytes in vivo, resulting in increased tensile strength of repaired tendons, suggesting a rationale for their clinical use for tendon injuries [12]. To clarify nomenclature, the isolated adipose-derived stem cell is commonly referred to as the ASC, while the regenerative cell mixture derived from collagenase digestion of adipose is more commonly called the stromal vascular fraction or adipose-derived regenerative cells (ADRCs). The treatments provided in this retrospectiuve study were with ADRCs. The clinical potential of ADRC therapy was demonstrated in horses using a collagenase-induced tendonitis model [13].

Numerous clinical reports of outcomes of the various treatment approaches to suspensory ligament desmitis have appeared in the literature. However, it is difficult to compare results of various treatments because of differing location of injury (origin, body, and/or branch), athletic activity of horses (racing, jumping, dressage, endurance, etc.), fore-limb and/or hind-limb involvement, and criteria for successful outcome (from a single lameness evaluation demonstrating resolution of lameness, to the ability to return to work but with no long-term follow-up). 
In our referral equine practice we have been treating suspensory ligament lesions (tears) with ADRCs for a decade. This report is a retrospective analysis of data from 83 horses with 176 tears of the suspensory ligament, treated with ADRCs, given a strictly enforced rehabilitation protocol, and for whom one year post treatment return to full work(RFW) follow up performance data were available.

\section{Materials and Methods}

\subsection{Case Records}

All cases were presented to a single referral hospital between the years 2005-2010. Complete medical records, documented rest and rehabilitation schedules, and return to performance data for at least 1 year, were available for these 83 horses. The majority of horses in this study were Western and English performance horses.

\subsection{Diagnostic Criteria}

All horses were clinically lame from their suspensory ligament injuries, and could no longer perform their athletic discipline because of their injuries. A diagnosis of suspensory ligament injury was made only after a thorough clinical lameness examination, diagnostic anesthesia, and ultrasound and/or MRI examination in all horses included in the study. Cases with inflamed, edematous ligaments without demonstrable tears were not included. Cases were categorized as acute or chronic (duration of injury for at least 3 months before treatment). Suspensory ligament tears were classified as fore-limb or hind-limb; origin, body, or branch; and mild, moderate, severe, or last resort. Cross-sectional areas of the ligament tears of the injured ligament segment determined the severity classification: Mild (5\% - 25\% cross-sectional area), Moderate (26\% - 50\% cross-sectional area), Severe (51\% - 75\% cross-sectional area), and Last Resort (76\% - 99\% cross-sectional area).

\subsection{Treatment}

Adipose tissue was surgically resected from the tail head region of each horse via a $2.5 \mathrm{~cm}$ incision, using light sedation, and an "inverted L block" regional anesthesia (Figure 1). The incisions were then closed in 2 layers; 3-0 Vicryl ${ }^{\mathrm{C}}$ subcutaneous, and 2-0 Ethilon ${ }^{\mathrm{d}}$ intradermal pattern in the skin. The adipose tissue was packaged in sterile containers containing sterile saline, and shipped overnight in a temperature controlled shipping system to a commercial laboratory ${ }^{\mathrm{a}}$. The cells were extracted using a method modified from Zuk using a combination of enzymatic digestion, washing, filtration and centrifugation [10]. After processing, nucleated cells were counted and cell viability was assessed using the ChemotecNucleocounter ${ }^{\mathrm{b}}$, a method that employs propidium iodide to demonstrate viable and non-viable nucleated cells. Samples for sterility evaluation were taken and any cells beyond those needed for the initial treatment were cryogenically preserved in dose aliquots. Forty-eight hours post-collection, fresh chilled cells $\left(2^{\circ} \mathrm{C}-8^{\circ} \mathrm{C}\right)$ were returned to the veterinary hospital in a temperature controlled shipping system.

The horses were pre-medicated with phenylbutazone $4.4 \mathrm{mg} / \mathrm{kg}$, sterile preps performed at the injection sites, and the suspensory tears were filled with ADRCs in a fan-like distribution throughout the injury site, using 21 or 22 gauge needles and ultrasonographic guidance. The volume of ADRCs injected varied depending on the size of the lesion, with the majority of injuries receiving between 0.6 to $2 \mathrm{~mL}$ volumes per injury site. Treatment doses averaged 6.8 million nucleated cells.

\subsection{Post-Treatment Follow-Up Evaluation, Rehabilitation, and Assessment of Return to Full Work}

All horses underwent the same rehabilitation program, beginning with 2.5 - 3 months hand walking 20 - 30 minutes per day, 4 - 5 days per week. Follow-up ultrasound examinations were performed on all injured suspensory ligament segments at approximately 6 and 12 weeks after treatment. When the injured ligament appeared healed on follow-up ultrasonographic examination and the horse was sound when trotted in hand, the horse was allowed to begin a 2-month graduated exercise program under saddle, followed by return to full work and/or competition (RFW). No turnout was authorized until RFW.

RFW status was determined by reviewing medical records for soundness, rehabilitation schedules, and owner survey to determine if the animal had remained in full work for a minimum of 1 year without re-injury. In addition, the level at which the horse was competing was categorized as pre-injury level (prior level), lower level, 


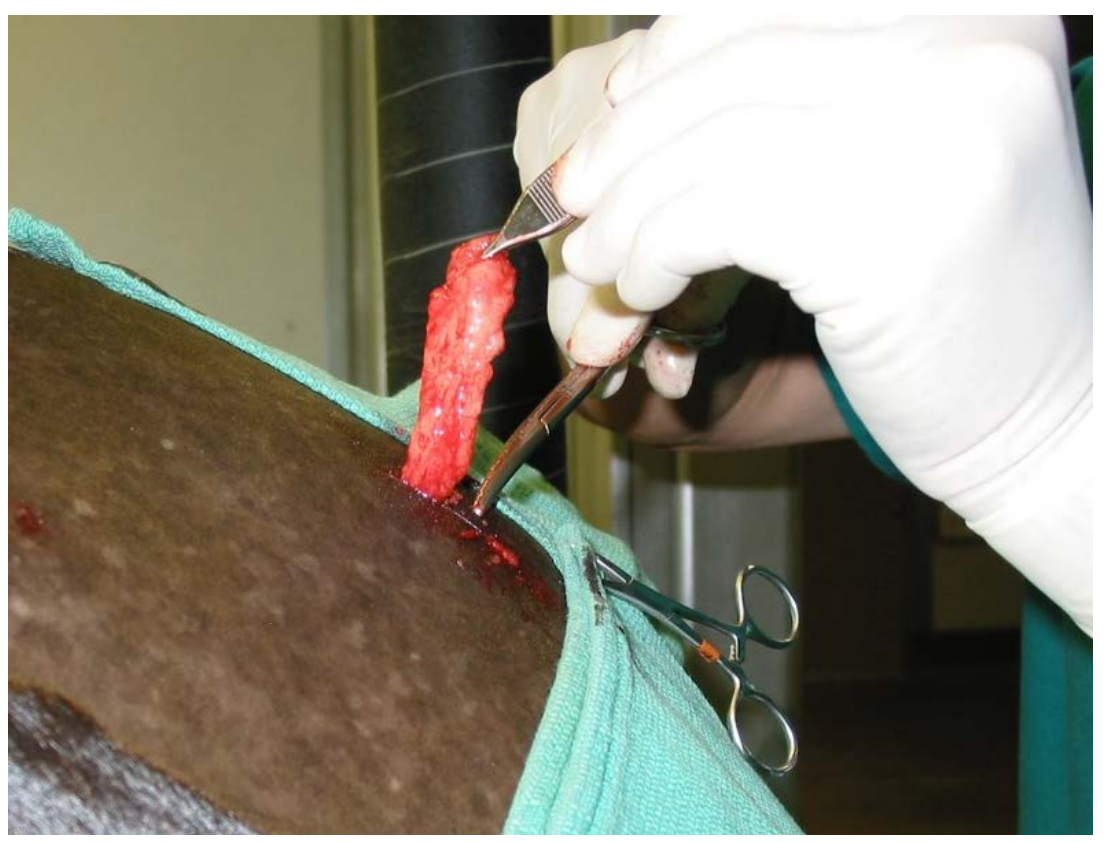

Figure 1. Aesthetic removal fat tissue from tail head region through a $2.5 \mathrm{~cm}$ incision.

or higher level. Horses were considered a success if they had a RFW at the previous or higher level of performance following treatment of their suspensory ligament tears, and remained at that level of performance for at least 1 year without re-injury. Horses were considered a failure if they had a RFW at a lower level of performance, developed a re-injury of the previously injured suspensory segment, or if their suspensory ligament tears did not heal.

\section{Results}

This series of cases consisted of 83 horses ranging in age from 1 to 19 years, engaged in strenuous athletic disciplines (Table 1). Quarterhorses and Warmbloods were the dominant breeds followed by Arabians and a few Thoroughbreds. Dressage, reigning/working cowhorse, jumper/eventing, western pleasure show horse, and endurance racing were the most frequent sport disciplines.

\subsection{Outcomes}

There were no adverse effects or local post injection flares in any of the 83 horses in this series. Overall, 84.3\% of the horses with suspensory lesions treated with ADRCs responded favorably, defined as return to full work (RFW) for 1 year or more at, or better than, pre-injury performance levels without re-injury. Ultrasonographic evidence of healing in a horse with a "last resort" suspensory injury before, and after ADRC therapy, is illustrated in Figure 2. Follow-up ranged from 13 to 92 months after RFW in all horses included in this study. Favorable RFW rates were similar in horses of various athletic disciplines (Table 2). Four of the horses competing as jumpers had other lameness problems that reduced their RFW performance. All of their suspensory injuries healed completely and did not contribute to the lower level of performance in these horses.

Time from injury to treatment had no apparent effect on the level of performance achieved after treatment with ADRCs. However, horses that had more secondary injuries to other structures in the same or different limbs during their rehabilitation, were more likely to have a negative outcome. Some of the horses with secondary injuries sustained these injuries while acting up during their extended layup periods, which delayed recovery and worsened outcome.

RFW rates were similar ( $>80 \%$ ) regardless of whether the suspensory injuries involved fore or hind-limbs, were mild, moderate or severe, acute or chronic (Table 3). All 3 horses, with both fore-limb and hind-limb suspensory ligament injuries, returned to former work without re-injury. Success rates were somewhat higher in horses with proximal suspensory lesions (86.7\%) than in those with lesions of the body or branches (Table 3). 
Table 1. Breed, age, sex, \& athletic discipline.

\begin{tabular}{cccc}
\hline & Number & \% & Age, mean \pm SD \\
\hline All horses & 83 & $100 \%$ & $9.0 \pm 4.0$ \\
Quarterhorse & 42 & $50.6 \%$ & $7.9 \pm 3.9$ \\
Warmblood & 22 & $26.5 \%$ & $10.1 \pm 3.5$ \\
Arabian & 14 & $16.9 \%$ & $10.0 \pm 4.1$ \\
Thoroughbred & 5 & $6.0 \%$ & $10.5 \pm 5.1$ \\
Gelding & 55 & $66.3 \%$ & $9.5 \pm 4.1$ \\
Mare & 22 & $26.5 \%$ & $8.4 \pm 3.9$ \\
Stallion & 6 & $7.2 \%$ & $7.1 \pm 2.7$ \\
Dressage & 23 & $27.7 \%$ & $10.2 \pm 3.7$ \\
Reining/working Cowhorse & 16 & $19.3 \%$ & $7.0 \pm 4.2$ \\
Jumper/eventing & 10 & $12.0 \%$ & $9.8 \pm 4.7$ \\
Western Pleasure Show & 10 & $12.0 \%$ & $8.8 \pm 2.0$ \\
Endurance Racing & 9 & $10.8 \%$ & $11.7 \pm 4.6$ \\
Barrel Racing & 7 & $8.4 \%$ & $7.7 \pm 2.5$ \\
Cutting Horse & 7 & $8.4 \%$ & $7.3 \pm 3.8$ \\
Thoroughbred Racing & 1 & $1.2 \%$ & 5.0 \\
\hline
\end{tabular}

Table 2. Outcome of horses with suspensory ligament injuries treated with adipose stem cells.

\begin{tabular}{|c|c|c|c|c|c|c|c|}
\hline \multirow{2}{*}{ Discipline } & \multirow{2}{*}{$\begin{array}{l}\text { Days from } \\
\text { injury to } \\
\text { treatment }\end{array}$} & \multirow{2}{*}{$\begin{array}{l}\text { Days from } \\
\text { treatment to } \\
\text { soundness }\end{array}$} & \multicolumn{4}{|c|}{$\geq 1$ year performance vs. pre-injury } & \multirow{2}{*}{$\begin{array}{c}\% \text { same } \\
\text { or better }\end{array}$} \\
\hline & & & Higher & Same & Lower & Retired & \\
\hline All disciplines, $n=83$ (100\%) & 71 & 98 & 19 & 51 & 12 & 1 & $84.3 \%$ \\
\hline Dressage, $n=23$ (28\%) & 45 & 92 & 7 & 15 & 1 & & $95.7 \%$ \\
\hline Reining/working, $\mathrm{n}=16$ (19\%) & 70 & 101 & 3 & 11 & 1 & 1 & $87.5 \%$ \\
\hline Jumper/eventing, $\mathrm{n}=10$ (12\%) & 44 & 92 & 1 & 3 & $6^{*}$ & & $40.0 \%$ \\
\hline Western Pleasure, $\mathrm{n}=10$ (12\%) & 115 & 109 & 2 & 6 & 2 & & $80.0 \%$ \\
\hline Endurance Racing, $n=9$ (11\%) & 115 & 97 & 2 & 6 & 1 & & $88.9 \%$ \\
\hline Barrel Racing, n = 7 (8\%) & 51 & 89 & 2 & 4 & 1 & & $85.7 \%$ \\
\hline Cutting Horse, $\mathrm{n}=7(8 \%)$ & 98 & 114 & 2 & 5 & & & $100.0 \%$ \\
\hline Thoroughbred Racing, 1 (1\%) & 58 & 91 & & 1 & & & $100.0 \%$ \\
\hline
\end{tabular}

*Four of the jumpers had lameness issues unrelated to suspensory lesions, which reduced their performance.

Table 3. Outcome by limb, severity, chronicity, and location.

\begin{tabular}{|c|c|c|c|c|c|}
\hline \multirow{2}{*}{ Grouping } & \multicolumn{2}{|c|}{$\geq 1$ year performance vs. pre-injury } & \multicolumn{3}{|c|}{$\geq 1$ year performance vs. pre-injury } \\
\hline & Higher & Same & Lower & Retired & Higher (RFW) \\
\hline Fore-limb only, n = 52 (63\%) & 10 & 34 & 7 & 1 & $84.6 \%$ \\
\hline Hind-limb only, n = 28 (34\%) & 7 & 16 & 4 & 1 & $82.1 \%$ \\
\hline Both fore- \&hind-limbs, $n=3$ (4\%) & 2 & 1 & 0 & 0 & $100.0 \%$ \\
\hline Mild, $\mathrm{n}=9(11 \%)$ & 1 & 7 & 0 & 1 & $88.9 \%$ \\
\hline Moderate, $n=57,(69 \%)$ & 14 & 33 & 10 & 0 & $82.5 \%$ \\
\hline Severe, $\mathrm{n}=16(19 \%)$ & 4 & 10 & 1 & 1 & $87.5 \%$ \\
\hline Last resort, $\mathrm{n}=1(1 \%)$ & 0 & 1 & 0 & 0 & $100.0 \%$ \\
\hline Acute, $\mathrm{n}=64,(77 \%)$ & 14 & 40 & 8 & 2 & $84.4 \%$ \\
\hline Chronic, $\mathrm{n}=19$ (23\%) & 5 & 11 & 3 & 0 & $84.2 \%$ \\
\hline Origin, $n=30(36 \%)$ & 7 & 19 & 4 & 0 & $86.7 \%$ \\
\hline Body, n = 6 (7\%) & 1 & 3 & 2 & 0 & $66.7 \%$ \\
\hline Branches, $\mathrm{n}=15$ (18\%) & 2 & 9 & 3 & 1 & $73.3 \%$ \\
\hline Multiple segments, $n=32$ (39\%) & 9 & 20 & 2 & 1 & $90.6 \%$ \\
\hline
\end{tabular}



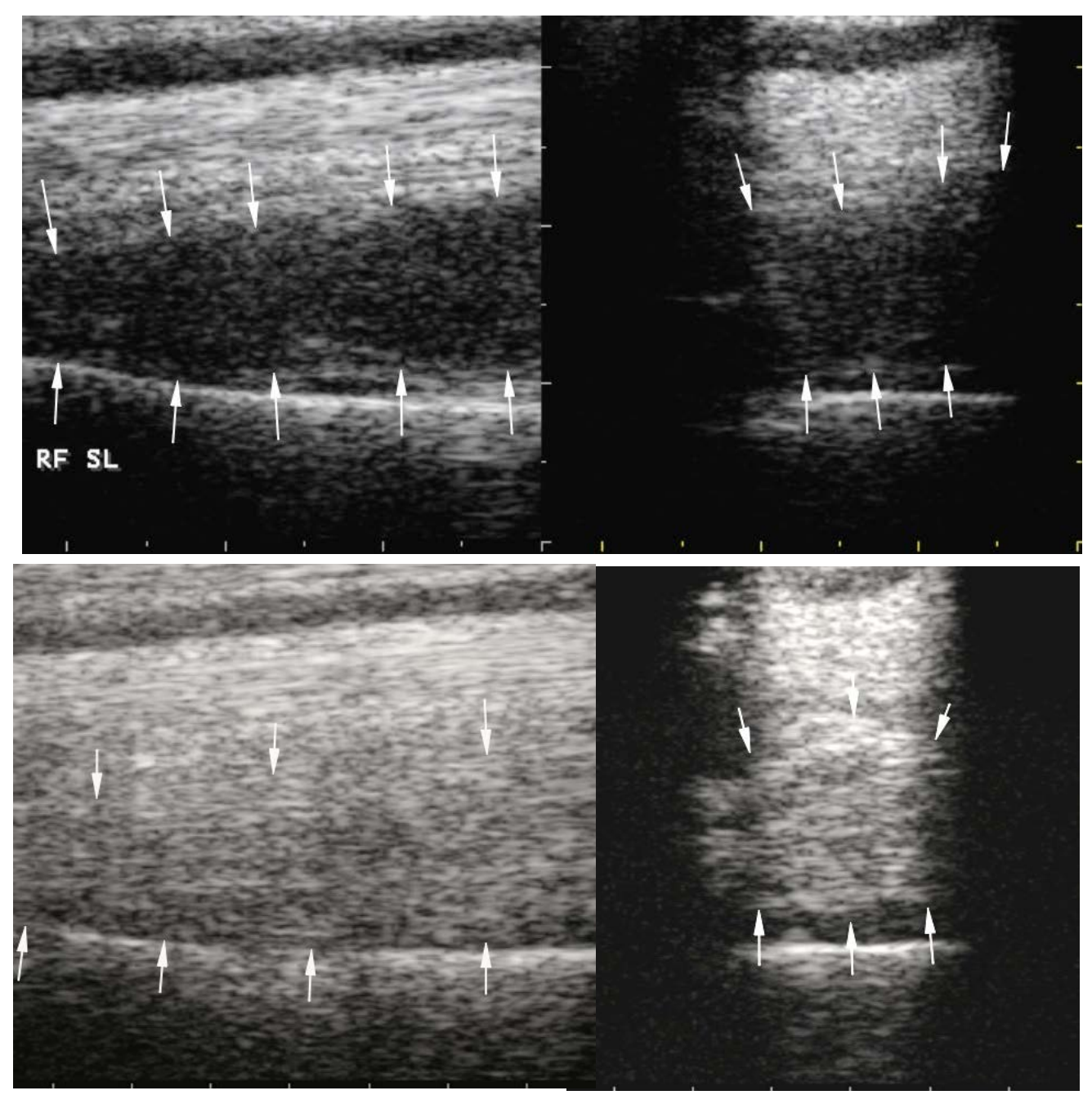

Figure 2. Ultrasonographs of suspensory ligament origin and body "last resort" lesions on day 1 of the injury before treatment (upper panels) and 94 days after treatment with adipose stem cells (lower panels). The suspensory ligament origin and body appeared normal on ultrasonographic examination at 94 days post- treatment.

Only 1 of the 83 horses re-injured when RFW. This horse had had multiple prior treatments, and was more than 20 months from the time of the original injury, when it was treated with ADRCs. It had severe scarring of the suspensory ligament origin and body, with peri-ligamentous adhesions throughout.

It is of interest to note the number and location of the suspensory ligament injuries encountered in this population of athletic horses (Table 4). The majority of the lesions were in the origin of the suspensory ligament, although the body and branches also had injuries as illustrated in Figure 3.

\subsection{Other Considerations}

Twenty-seven of the horses (32\%) had medical record evidence of receiving previous failed treatments for their suspensory ligament injuries prior to this author's treatment with ADRCs. Previous treatments included corticosteroids, ESWT, surgery (fasciotomy, retinacular release), PRP, biomatrix, IRAP, and combinations of the aforementioned. In our series of cases, the RFW-Prior or Higher level for these horses that had received prior treatment without healing their suspensory injuries, or with re-injury after treatment, was similar to those with no history of previous treatment. Four horses (4.7\%) had concurrent avulsion fractures. Of these, 3 horses returned to RFW-Prior or higher level of performance, and 1 horse RFW-Lower level. Of 10 bilateral fore-limb or bilateral hind-limb cases, 8 RFW-Prior or Higher level, and 2 RFW-Lower level. 
Table 4. Number and location of suspensory ligament lesions.

\begin{tabular}{ccccc}
\hline Grouping & \multicolumn{4}{c}{ Location \& number of lesions (average) } \\
\cline { 2 - 5 } All horses, $\mathrm{n}=83(100 \%)$ & Origin & Body & Branch & All lesions \\
Dressage, $\mathrm{n}=23(28 \%)$ & $72(1.2)$ & $40(1.2)$ & $64(2.0)$ & $176(2.1)$ \\
Reining/working, $\mathrm{n}=16(19 \%)$ & $19(1.3)$ & $15(1.4)$ & $16(1.6)$ & $50(2.2)$ \\
Jumper/eventing, $\mathrm{n}=10(12 \%)$ & $11(1.0)$ & $7(1.0)$ & $6(1.5)$ & $24(1.5)$ \\
Western Pleasure, $\mathrm{n}=10(12 \%)$ & $8(1.1)$ & $3(1.0)$ & $8(2.0)$ & $19(1.9)$ \\
Endurance Racing, $\mathrm{n}=9(11 \%)$ & $5(1.0)$ & $4(1.0)$ & $5(1.7)$ & $14(1.4)$ \\
Barrel Racing, $\mathrm{n}=7(8 \%)$ & $10(1.3)$ & $2(2.0)$ & $9(4.5)$ & $21(2.3)$ \\
Cutting Horse, $\mathrm{n}=7(8 \%)$ & $8(1.6)$ & $4(1.3)$ & $6(1.5)$ & $18(2.6)$ \\
Thoroughbred racing, $\mathrm{n}=1$ & $10(1.4)$ & $5(1.3)$ & $14(2.0)$ & $29(4.1)$ \\
Fore-limb only, $\mathrm{n}=52(63 \%)$ & 1 & & & 1 \\
Hind-limb only, $\mathrm{n}=28(34 \%)$ & $42(1.1)$ & $26(1.1)$ & $28(1.8)$ & $96(1.8)$ \\
Fore- \& hind-limb, $\mathrm{n}=3(4 \%)$ & $24(1.3)$ & $13(1.4)$ & $25(1.9)$ & $62(2.2)$ \\
Mild, $\mathrm{n}=9(11 \%)$ & $6(2.0)$ & $1(1.0)$ & $11(3.7)$ & $18(6.0)$ \\
Moderate, $\mathrm{n}=57$ (69\%) & $5(1.0)$ & $5(1.3)$ & $5(1.9)$ & $25(2.8)$ \\
Severe, $\mathrm{n}=16(19 \%)$ & $46(1.2)$ & $20(1.1)$ & $35(1.8)$ & $101(1.8)$ \\
Last resort, $\mathrm{n}=1$ & $20(1.5)$ & $141.4)$ & $12(1.4)$ & $46(2.9)$ \\
Acute, $\mathrm{n}=$ 64 (77\%) & 1 & 1 & 2 & 4 \\
Chronic, $\mathrm{n}=19(23 \%)$ & $53(1.2)$ & $29(1.1)$ & $36(1.6)$ & $118(1.8)$ \\
\hline
\end{tabular}

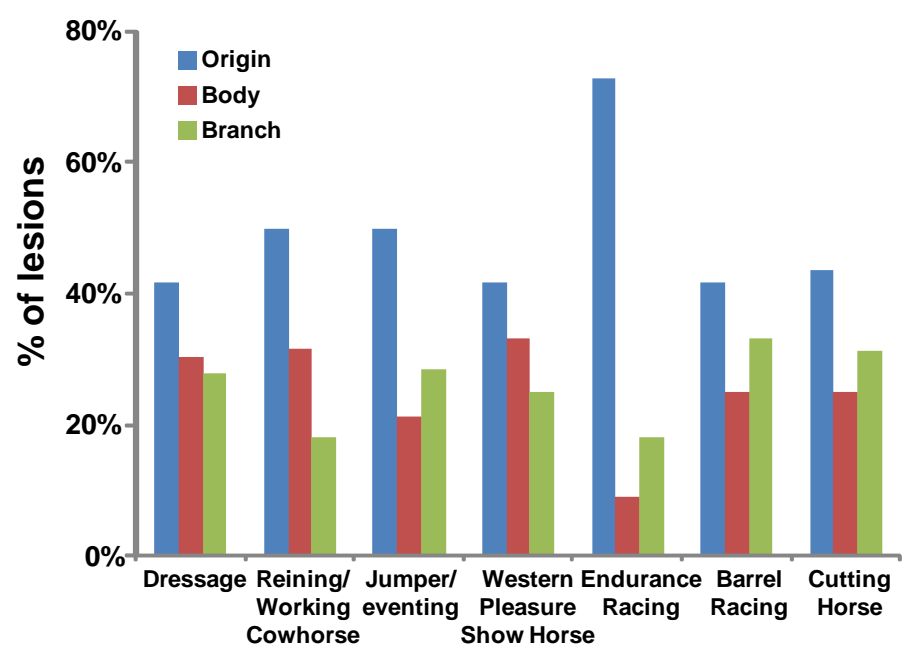

Figure 3. Distribution of the location of suspensory injury by sport discipline.

\section{Discussion}

This retrospective study focused on results of ADRC treatment in a large series of clinical cases of suspensory injuries at a single equine surgical and diagnostic imaging practice, employing standardized aftercare and a stringent criterion for success: RFW at their prior or higher level of performance for greater than 1 year, without re-injury. One of the purposes of this report is to provide a detailed breakdown of the suspensory lesions and results of ADRC treatment, in order to facilitate comparisons with outcomes of other treatments.

RFW numbers presented here ( $84.6 \%$ fore-limb, $82.1 \%$ hind-limb) compare favorably to other reported treatments. Had the 4 jumpers not had other lameness issues decreasing their performance level, they would 
likely have returned to their prior level of performance instead of to a lower level of performance. This falsely lowered our success rate for these horses (see Table 2), and our overall success rates. Published results of other treatments varied greatly depending on the ligament section involved (origin, body, or branches), whether the injury involved fore-limbs or hind-limbs, and the activity level of the horses. Success rates reported for other treatments also varied as a function of stringency of the definition of success, ranging from resolution of lameness based on a single evaluation, vs. ability to RFW without any follow-up, vs. return to previous level of work for a period of 1 year or more without re-injury.

Rest alone followed by controlled walking and gradual return to exercise is reportedly successful in horses with proximal suspensory desmitis of the fore-limb, but much less successful in hind-limb disease [6]. In our experience, many horses with suspensory injuries can trot off sound after an extended rest period, or RFW briefly, before they become lame again from their suspensory injuries, or reinjure the same suspensory injury. We feel that a true measure of success cannot be determined without long term follow-up data after returning to full work. Surgery (desmoplasty and/or fasciotomy), in athletic horses with chronic, proximal suspensory (origin) desmitis, was reportedly $85 \%$ successful, defined as returning to "the level of activity desired by the owner" [2]. Radial extracorporeal shock wave therapy (ESWT), in 30 horses with chronic proximal suspensory desmopathy, resulted in 60\% returning to full work within 6 months [14]. In 45 mature competition horses with chronic hind-limb proximal suspensory desmitis, ESWT enabled $41 \%$ of the cases to return to their previous occupation 6 months after diagnosis [15]. Long-term follow-up evaluation was not reported in most studies, making it difficult to directly compare our results with those of others.

Autologous regenerative therapies that have been applied to equine suspensory desmitis include platelet rich plasma (PRP), bone marrow aspirates [16], bone marrow-derived mesenchymal stem cells [17], and adiposederived stem cells [18]. PRP contains endogenous growth factors that are intended to facilitate healing and earlier return to sport following musculoskeletal injury [8] [9]. In a clinical trial involving 9 yearling standardbred race horses with ultrasound-documented suspensory branch desmitis treated with PRP, all were able to start at least 1 race during their 2 year old year of racing [19]. In 39 racing Thoroughbreds with inflammation of the proximal suspensory branches and sesamoid bones, however, no significant differences in outcome between saline and PRP treatment groups were found for any racing year [20].

Adipose tissue is an abundant source of adult stem cells. The principal cell type in the stromal vascular fraction (SVF) is the ASC, and although variable, the SVF contains approximately 44\% ASCs [21]. There are many similarities between ASCs and MSCs in terms of their growth, morphology, gene expression, and cell surface profiles. ASCs have been shown to possess immunomodulatory properties equivalent to, or greater than those of bone marrow-derived stem cells [22]-[24]. The effect ADRCs have on healing equine tendons and ligaments was demonstrated in a collagenase model of superficial digital flexor tendonitis in horses [13]. Intralesional injection of ADRCs improved the gross and histological morphology of healing tendons and significantly increased cartilage oligomeric matrix protein gene expression compared with controls. In terms of mechanism, ADRCs also contribute to tissue healing indirectly through the production of bioactive proteins including growth factors, chemotactic agents, and anti-apoptotic factors [25]. Acting together, these secreted proteins can stimulate vascular ingrowth as well as recruit additional adult stem cells to further stimulate healing. Blocking apoptosis (programmed cell death) is another possible mechanism, in light of the finding that apoptosis is part of the pathogenesis of equine tendonitis [26].

A previous retrospective study examined the medical records of cases of suspensory ligament injury in horses following treatment with ADRCs [18]. Acute injuries $(n=6)$ were a small proportion of the overall injuries, and showed $100 \%$ return to full work at the prior level. This was compared to $73.9 \%$ of those with chronic injuries, which encompassed $88 \%$ of the horses. Horses with chronic injury had been treated with several modalities prior to treatment with regenerative cell therapy. The return to performance numbers supported the therapeutic use of regenerative cells extracted from adipose tissue for treatment of acute and chronic suspensory desmitis, with or without avulsion fractures.

The results presented herein compare favorably with those of other studies. However, this study is the first to have only one clinician perform all of the clinical exams and to follow standardized rehabilitation protocols. This study also involved more suspensory ligament cases and lesions than those in the previous studies. Furthermore, the criterion for a positive outcome was more stringent in this study than that in any of the previous reports (evaluation after 1 year of full work, rather than evaluation one year after treatment). The long term stability of healed lesions, documented by stringent follow-up criteria, strongly supports the therapeutic use of re- 
generative cells extracted from adipose tissue for treatment of acute and chronic, fore- and hind-limb, origin, body, and branch suspensory ligament injuries.

\section{References}

[1] Smith, R.K.W. (2005) Physiology of Tendon and Ligament. In: Chuit, P. and Montavon, S., Eds., 9th Congress on Equine Medicine \& Surgery, International Veterinary Information Service, Geneva, 1903-1905.

[2] Hewes, C.A. and White, N.A. (2006) Outcome of Desmoplasty and Fasciotomy for Desmitis Involving the Origin of the Suspensory Ligament in Horses: 27 Cases (1995-2004). Journal of the American Veterinary Medical Association, 229, 407-412. http://dx.doi.org/10.2460/javma.229.3.407

[3] Dyson, S.J. and Genovese, R.L. (2003) The Suspensory Apparatus. In: Ross, M. and Dyson, S., Eds., Diagnosis and Management of Lameness in the Horse, Saunders, St. Louis, 654-666. http://dx.doi.org/10.1016/B978-0-7216-8342-3.50080-2

[4] Ross, M.W. (2006) Suspensory Desmitis-Management Options.

[5] Cowles, R.R. (2000) Proximal Suspensory Desmitis-A Qualitative Survey. Proceedings of the Annual Convention-American Association of Equine Practitioners, 46, 143-144.

[6] Dyson, S. (2000) Proximal Suspensory Desmitis in the Forelimb and the Hindlimb. Proceedings of the Annual Convention-American Association of Equine Practitioners, 46, 137-142.

[7] Dahlgren, L. (2005) Review of Treatment Options for Equine Tendon and Ligament Injuries: What's New and How do They Work? Proceedings of the Annual Convention-American Association of Equine Practitioners.

[8] Textor, J. (2011) Autologous Biologic Treatment for Equine Musculoskeletal Injuries: Platelet-Rich Plasma and IL-1 Receptor Antagonist Protein. Veterinary Clinics of North America: Equine Practice, 27, 275-298. http://dx.doi.org/10.1016/j.cveq.2011.05.001

[9] Bosch G., Moleman M., Barneveld A., van Weeren P.R. and van Schie H.T.M. (2011) The Effect of Platelet-Rich Plasma on the Neovascularization of Surgically Created Equine Superficial Digital Flexor Tendon Lesions. Scandinavian Journal of Medicine \& Science in Sports, 21, 554-561. http://dx.doi.org/10.1111/j.1600-0838.2009.01070.x

[10] Zuk, P.A., Zhu, M. and Ashjian, P. (2002) Human Adipose Tissue Is a Source of Multipotent Stem Cells. Molecular Biology of the Cell, 13, 4279-4295. http://dx.doi.org/10.1091/mbc.E02-02-0105

[11] Park, A., Hogan, M., Kesturu, G., et al. (2010) Adipose-Derived Mesenchymal Stem Cells Treated with Growth Differentiation Factor-5 Expresstendon-Specific Markers. Tissue Engineering, 16, 2941-2951.

[12] Uysal, A.C. and Mizuno, H. (2010) Tendon Regeneration and Repair with Adipose Derived Stem Cells. Current Stem Cell Research \& Therapy, 5,161-167. http://dx.doi.org/10.2174/157488810791268609

[13] Nixon, A.J., Dahlgren, L.A., Haupt, et al. (2008) Effect of Adipose Derived Nucleated Cell Fractions on Tendon Repair in Horse with Collagenase-Induced Tendinitis. American Journal of Veterinary Research, 69, 928-937.

[14] Boening, K.J., Loffeld, S., Weitkamp, K. and Matuschek, S. (2000) Radial Extracorporeal Shock Wave Therapy for Chronic Insertion Desmopathy of the Proximal Suspensory Ligament. Proceedings of the Annual Convention-American Association of Equine Practitioners, 46, 203-207.

[15] Crowe, O., Dyson, S.J., Wright, I.M., et al. (2002) Treatment of 45 Cases of Chronic Hindlimb Proximal Suspensory Desmitis by Radial Extracorporeal Shockwave Therapy. Proceedings of the Annual Convention-American Association of Equine Practitioners, 48, 322-325.

[16] Herthel, D.J. (2001) Enhanced Suspensory Ligament Healing in 100 Horses by Stem Cells and Other Bone Marrow Components. Proceedings of the Annual Convention-American Association of Equine Practitioners, 47, 319-321.

[17] Ferris, D.J., Kisiday, J.D., McIlwraith, C.W., et al. (2009) Clinical Follow-Up of Horses Treated with Bone MarrowDerived Mesenchymal Stem Cells for Musculoskeletal Lesions. Proceedings of the Annual Convention-American Association of Equine Practitioners, 55, 59-60.

[18] Harman, R.J., Cowles, B.C., Orava, J.C. and Harman, S.P. (2007). A Retrospective Review of 52 Cases of Suspensory Ligament Injury in Sport Horses Treated with Adipose-Derived Stem and Regenerative Cell Therapy. Proceedings of Veterinary Orthopedic Society, 34, 28.

[19] Waselau, M., Sutter, W, Genovese, R. and Bertone, A. (2008) Intralesional Injection of Platelet-Rich Plasma Followed by Controlled Exercise for Treatment of Midbody Suspensory Ligament Desmitis in Standardbred Racehorses. Journal of the American Veterinary Medical Association, 232, 1515-1520. http://dx.doi.org/10.2460/javma.232.10.1515

[20] Garrett, K.S., Bramlage, L.R, Spike-Pierce, D.L. and Cohen, N.D. (2013) Injection of Platelet- and Leukocyte-Rich Plasma at the Junction of the Proximal Sesamoid Bone and the Suspensoryligament Branch for Treatment of Yearling Thoroughbreds with Proximal Sesamoid Bone Inflammation and Associated Suspensory Ligament Branch Desmitis. 
Journal of the American Veterinary Medical Association, 243, 120-125. http://dx.doi.org/10.2460/javma.243.1.120

[21] Vidal, M., Kilroy, G., Lopez, M., et al. (2007) Characterization of Equine Adipose Tissue-Derived Stromal Cells: Adipogenic and Osteogeniccapacity and Comparison with One Marrow-Derived Mesenchymal Stromal Cells. Veterinary Surgery, 36, 613-622. http://dx.doi.org/10.1111/j.1532-950X.2007.00313.X

[22] Bochev, I., Elmadjian, G., Kyurkchiev, D., et al. (2008) Mesenchymal Stem Cells from Human Bone Marrow or Adiposetissue Differently Modulate Mitogen-Stimulated B-Cellimmunoglobulin Production in Vitro. Cell Biology International, 32, 384-393. http://dx.doi.org/10.1016/j.cellbi.2007.12.007

[23] Tholpady, S.S., Ogle, R.C. and Katz, A.J. (2009) Adipose Stem Cells and Solid Organ Transplantation. Current Opinion in Organ Transplantation, 14, 51-55. http://dx.doi.org/10.1097/MOT.0b013e328320d2cf

[24] Melief, S.M., Zwaginga, J.J., Fibbe, W.E. and Roelofs, H. (2013) Adipose-Derived Multipotent Stromal Cells Have a Higher Immunomodulatory Capacity Than Their Bone Marrow Counterparts. Stem Cells Translational Medicine, 2, 455-463. http://dx.doi.org/10.5966/sctm.2012-0184

[25] Caplan, A. (2006) Mesenchymal Stem Cells as Trophic Mediators. Journal of Cellular Biochemistry, 98, $1076-1084$. http://dx.doi.org/10.1002/jcb.20886

[26] Hosaka, Y. Teraoka, H., Yamamoto, E., et al. (2005) Mechanism of Cell Death in Inflamed Superficial Digital Flexor Tendon in the Horse. Journal of Comparative Pathology, 132, 51-58. http://dx.doi.org/10.1016/j.jcpa.2004.06.006 